Article

\title{
Synthesis, Biological Activity, and Apoptotic Properties of NO-Donor/Enmein-Type ent-Kauranoid Hybrids
}

\author{
Dahong $\mathrm{Li}^{1,2,3}, \mathrm{Xu} \mathrm{Hu}^{1}$, Tong Han ${ }^{1}$, Shengtao $\mathrm{Xu}^{4}$, Tingting Zhou ${ }^{1}$, Zhenzhong Wang ${ }^{2, *}$, \\ Keguang Cheng ${ }^{3}$, Zhanlin $\mathrm{Li}^{1}{ }^{1}$, Huiming Hua ${ }^{1, *}$, Wei Xiao ${ }^{2}$ and Jinyi $\mathrm{Xu}^{4, *}$ \\ 1 Key Laboratory of Structure-Based Drug Design \& Discovery, Ministry of Education, \\ and School of Traditional Chinese Materia Medica, Shenyang Pharmaceutical University, \\ Shenyang 110016, China; lidahong0203@163.com (D.L.); huxu105@163.com (X.H.); \\ hantong1221@163.com (T.H.); tingtingzhou1118@hotmail.com (T.Z.); lzl1030@hotmail.com (Z.L.) \\ 2 State Key Laboratory of New-Tech for Chinese Medicine Pharmaceutical Processes, \\ and National Post-Doctoral Research Workstation, Jiangsu Kanion Pharmaceutical Co., Ltd., \\ Lianyungang 222001, China; kanionxw2010@126.com \\ 3 State Key Laboratory for the Chemistry and Molecular Engineering of Medicinal Resources, \\ and School of Chemistry and Pharmacy, Guangxi Normal University, Guilin 541004, China; \\ kgcheng2008@gmail.com \\ 4 Department of Medicinal Chemistry and State Key Laboratory of Natural Medicines, \\ China Pharmaceutical University, Nanjing 210009, China; cpuxst@163.com \\ * Correspondence: kanionwzz2016@126.com (Z.W.); huimhua@163.com (H.H.); jinyixu@china.com (J.X.); \\ Tel.: +86-24-2398-6465 (H.H.); +86-25-8327-1445 (J.X.)
}

Academic Editor: Ge Zhang

Received: 26 February 2016; Accepted: 6 May 2016; Published: 24 May 2016

\begin{abstract}
Herein, we reported on a series of synthetic nitric oxide-releasing enmein-type diterpenoid hybrids (9a-i). All the target compounds showed potent antibacterial activity against selected Gram-positive bacteria $S$. aureus and B. subtilis. The antiproliferative activity against human tumor K562, MGC-803, CaEs-17 and Bel-7402 cells, and human normal liver cells L-02 was tested and the structure activity relationships (SARs) were also concluded. Compounds $\mathbf{9 b}$ and $\mathbf{9 d}$ showed the best activity against $S$. aureus and $B$. subtilis with the same minimal inhibitory concentrations (MICs) of 4 and $2 \mu \mathrm{g} / \mathrm{mL}$, respectively. The derivative $9 \mathrm{f}$ displayed $\mathrm{IC}_{50}$ values of 1.68, 1.11, 3.60 and $0.72 \mu \mathrm{M}$ against the four cancer cell lines above and $18.80 \mu \mathrm{M}$ against normal liver cells L-02; meanwhile, 9f also released a high level of $\mathrm{NO}$ at the time point of $60 \mathrm{~min}$ of $22.24 \mu \mathrm{mol} / \mathrm{L}$. Furthermore, it was also found that 9f induced apoptosis via the mitochondria-related pathway and arrested cell cycle of Bel-7402 cells at $S$ phase. These findings might be important to explore new chemical entities for the main causes of in-hospital mortality of $S$. aureus infection, combined with a solid tumor.
\end{abstract}

Keywords: NO-donor; enmein-type; ent-kauranoid; antiproliferative; apoptosis

\section{Introduction}

Bacterial infections, causing deadly diseases, have increased at an alarming rate [1,2]. The development of drug resistance among the infectious bacterial strains and absence of effective preventive measures have become the two major driving forces for design and identify suitable active new chemical entities. On the other hand, cancer, uncontrolled, rapidly proliferating, abnormal cells, is now the second leading cause of human deaths, and the high mortality rate engages with the rising number of diverse cancer types [3]. These have triggered research aiming to find new lead structures that may be beneficial in the design of novel antitumor agents [4,5]. Patients with neoplastic disorders 
are subjected to chemotherapeutic treatment, and susceptible to microbial infections due to the poor immunity [6]. For example, Staphylococcus aureus is a pathogen responsible for the main causes of in-hospital mortality [7]. Therefore, the discovery of new novel potent antibacterial and antitumor chemical entities is challenging work for medicinal chemists [8-11].

A potential solution is to explore innovative natural scaffolds from natural sources [12,13]. Among numerous exploited medicinal plants, the Isodon species are traditionally used as antitumor and antibacterial folk medicine and have many complex and bioactive diterpenoids $[14,15]$. They have recently received great attention from researchers from many research fields [16-18]. In this context, enmein-type ent-kauranoids, one of the important and main classes of diterpenoids from the plants of Isodon species with antitumor and antibacterial activities, are worthy of intensive investigation.

Nitric oxide (NO) is an endogenous, small and reactive molecule, which has various physiological and biological properties [19-21]. High concentration of NO is cytotoxic to tumor cells by inducing tumor cell apoptosis, sensitizing drug-resistant tumor cells, and inhibiting tumor metastasis, and so on $[22,23]$. NO also exhibits antimicrobial activity and kills bacteria through lipid peroxidation, DNA cleavage, and protein dysfunction. The multiple bactericidal pathways of NO make it a potent broad-spectrum antimicrobial agent with low risk [24-26]. Thus, NO-donating groups are good pharmacophores for both antitumor and antibacterial agents.

On the basis of the above, we developed a series of new enmein-type ent-kauranoid derivatives containing furozan-based NO-donors. The antibacterial potency, antiproliferative activity and NO releasing ability of target compounds were tested. Furthermore, the preliminary antitumor mechanisms were also disclosed.

\section{Results and Discussion}

\subsection{Chemistry}

Diphenylsulfonylfuroxan (4) was obtained in a three-step sequence starting from benzenethiol (1), and was then treated with corresponding diol to afford monophenylsulfonylfuroxans $(\mathbf{5 a}-\mathbf{c})$. Furoxan-based NO donors intermediate $\mathbf{6 a - i}$ were obtained from the condensation of $\mathbf{5 a - c}$ with corresponding anhydride. Enmein-type ent-kauranoid derivative 8 was synthesized from oridonin (7) by treatment with sodium periodate in water. Target NO donor/enmein-type ent-kauranoid hybrids $9 \mathbf{9}-\mathbf{i}$ were designed and synthesized from $\mathbf{8}$ with $\mathbf{6 a}-\mathbf{i}$ in the presence of DMAP/EDCI in DCM. Flash chromatography was used only at the last step of the synthetic route of each target compound (Scheme 1) [22,27].

\subsection{Antimicrobial Activity}

The antibacterial activity of NO donor/enmein-type ent-kauranoid hybrids $9 a-\mathbf{i}$ against the Gram-negative bacterium Escherichia coli (ATCC 25922), Gram-positive bacterium Staphylococcus aureus (ATCC 29213) and Bacillus subtilis (CMCC 63501), and the fungus Monilia albicans (ATCC 10231) was first disclosed and summarized in Table 1. Parent compound enmein-type 6,7-seco-ent-kauranoid 8 showed the minimum inhibitory concentration (MIC) above $100 \mu \mathrm{g} / \mathrm{mL}$ and derivatives $9 \mathbf{a}-\mathbf{i}$ exhibited antibacterial activity against gram-positive bacterium S. aureus and B. subtilis to some extent. In the $S$. aureus strain, $\mathbf{9 a - i}$ exhibited similar or stronger antibacterial activity than $\mathbf{7}$, which meant that structural modifications introduced going in the right direction, improving its biological properties. In the B. subtilis strain, $\mathbf{9 b} \mathbf{b} \mathbf{d}$ and $\mathbf{9 i}$ were even more potent than positive control chloromycetin. Thus, the introduction of NO-donor substituent groups at the 14-position of enmein-type 6,7-seco-ent-kauranoid could improve antimicrobial activity against S. aureus and B. subtilis. However, almost all of them were inactive (MIC $>100 \mu \mathrm{g} / \mathrm{mL}$ ) against E. coli and M. albicans, and target compounds selectively inhibited Gram-positive bacteria S. aureus and B. Subtilis. 

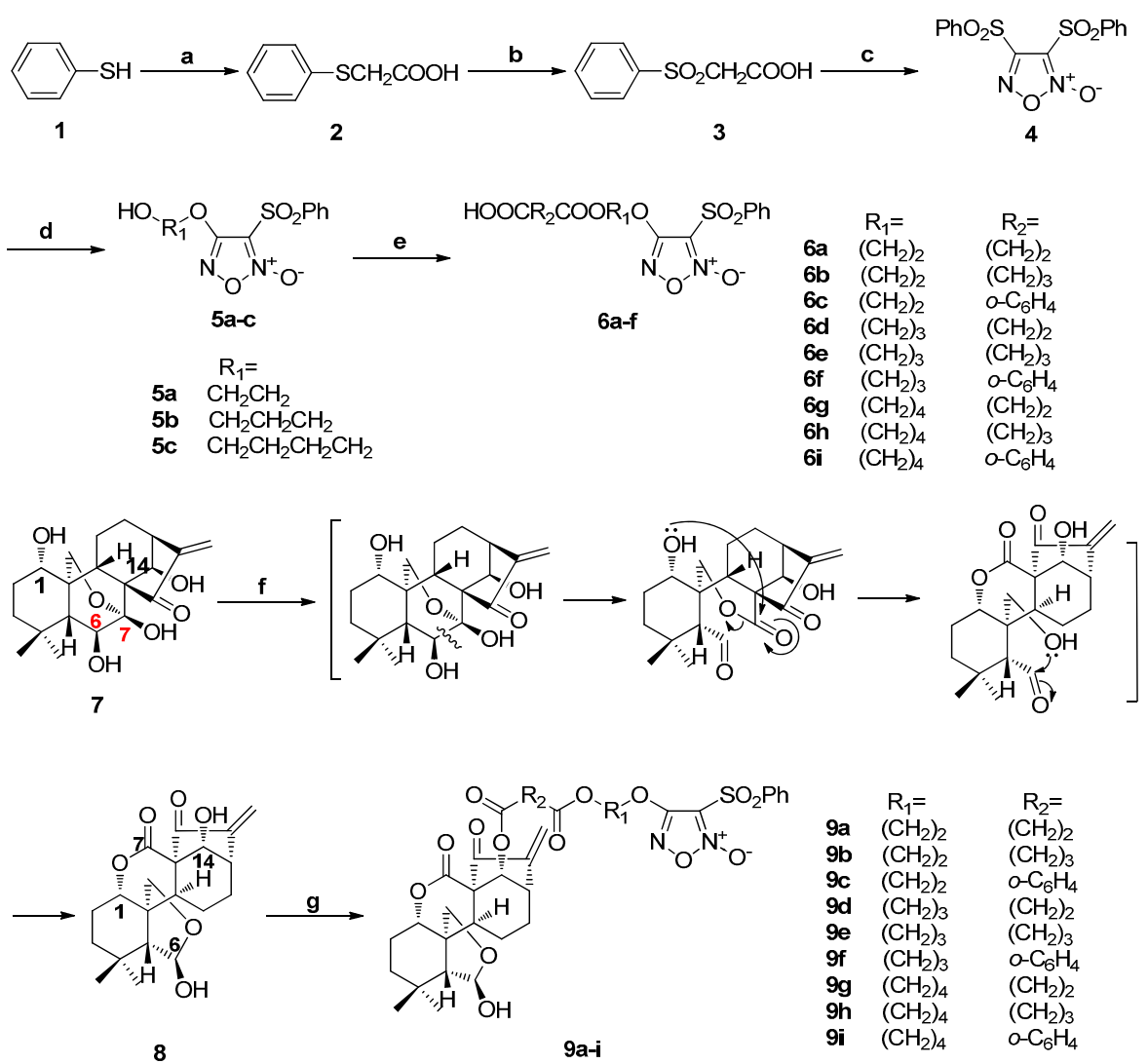

Scheme 1. Synthesis of NO donor/enmein-type ent-kauranoid hybrids 9a-i. Reagents and conditions: (a) $\mathrm{ClCH}_{2} \mathrm{COOH}, \mathrm{NaOH}(\mathrm{aq}), 140{ }^{\circ} \mathrm{C}, 2 \mathrm{~h}$; (b) $30 \% \mathrm{H}_{2} \mathrm{O}_{2}, \mathrm{AcOH}, \mathrm{rt}, 3 \mathrm{~h}$; (c) fuming $\mathrm{HNO}_{3}, 90{ }^{\circ} \mathrm{C}, 4 \mathrm{~h}$; (d) diol, THF, 30\% NaOH, $0{ }^{\circ} \mathrm{C}, 4-8 \mathrm{~h}$; (e) triethylamine, succinic anhydride, DMAP, rt, $1 \mathrm{~h}$; (f) $\mathrm{NaIO}_{4}$, $\mathrm{H}_{2} \mathrm{O}$, rt, 6 h; (g) 6, EDCI, DMAP, rt, 12 h.

Table 1. The antimicrobial activity of the synthesized compounds (MIC $\mu \mathrm{g} / \mathrm{mL}$ ).

\begin{tabular}{ccccc}
\hline Compound & E. coli & S. aureus & B. subtilis & M. albicans \\
\hline $\mathbf{7}$ & $>100$ & 32 & 32 & $>100$ \\
$\mathbf{8}$ & $>100$ & $>100$ & $>100$ & $>100$ \\
$\mathbf{9 a}$ & $>100$ & 16 & 64 & $>100$ \\
$\mathbf{9 b}$ & $>100$ & 4 & 2 & $>100$ \\
$\mathbf{9 c}$ & $>100$ & 8 & 4 & $>100$ \\
$\mathbf{9 d}$ & $>100$ & 4 & 2 & $>100$ \\
$\mathbf{9 e}$ & $>100$ & 16 & 16 & $>100$ \\
$\mathbf{9 f}$ & $>100$ & 32 & 64 & $>100$ \\
$\mathbf{9 g}$ & $>100$ & 16 & 16 & $>100$ \\
$\mathbf{9 h}$ & $>100$ & 16 & 16 & $>100$ \\
$\mathbf{9 i}$ & $>100$ & 16 & 2 & $>100$ \\
Chloromycetin & 4 & 4 & 8 & $\mathrm{NT}$ \\
Fluconazole & $\mathrm{NT}$ & $\mathrm{NT}$ & $\mathrm{NT}$ & 4 \\
\hline
\end{tabular}

${ }^{1} \mathrm{NT}$, not test.

The most promising compounds $9 \mathrm{~b}$ and $\mathbf{9 d}$ exhibited the strongest antibacterial activity among 9a-i with MICs of 4 and $2 \mu \mathrm{g} / \mathrm{mL}$ against $S$. aureus and B. subtilis. The substituents $\left(\mathrm{R}_{1}\right.$ and $\left.\mathrm{R}_{2}\right)$ of $9 \mathbf{b}$ were $\left(\mathrm{CH}_{2}\right)_{2}$ and $\left(\mathrm{CH}_{2}\right)_{3}$, respectively, while the substituents were $\left(\mathrm{CH}_{2}\right)_{3}$ and $\left(\mathrm{CH}_{2}\right)_{2}$ of $9 \mathbf{d}$. Coincidentally, two of the most active compounds, $9 \mathrm{~b}$ and $9 \mathrm{~d}$, had the same total linkage length of five carbons $\left(\mathrm{CH}_{2}\right)_{5}$. The linkages between NO donor and parent compound always affected the biological activity. Different lead compounds had their own favorable linker [22,23,28,29]. 


\subsection{Antiproliferative Activity}

The antiproliferative activity of $9 \mathbf{a}-\mathbf{i}$ against four human cancer cell lines K562 leukemia cell line, MGC-803 gastric cancer cell line, CaEs-17 esophageal cancer cell line, and Bel-7402 hepatoma cell line, and human normal liver cells L-02 was evaluated by MTT assay (Table 2). All the target molecules $9 \mathbf{a}-\mathbf{i}$ were stronger than oridonin 7 with $\mathrm{IC}_{50}$ values below $1.33 \mu \mathrm{M}$ and lower than Taxol $(1.89 \mu \mathrm{M})$ against Bel-7402 cell line. The most potent $9 \mathrm{f}$ with $\mathrm{IC}_{50}$ of $0.72 \mu \mathrm{M}$ was 1 -fold stronger than Taxol. While, target compounds were not so sensitive to CaEs-17 cells with $\mathrm{IC}_{50}$ ranging from 3.60 to $5.13 \mu \mathrm{M}$. $\mathrm{IC}_{50}$ values against MGC-803 cell line were a little weaker than Taxol, between 1.11 to $1.83 \mu \mathrm{M}$. For K562 cell line, the antiproliferative activity of all the derivatives was weaker than Taxol. Most NO donor derivatives showed cytotoxic selectivity between tumor and normal liver cells to some extent, with $\mathrm{IC}_{50}$ values ranging from 10.36 to $19.87 \mu \mathrm{M}$ against L-02 normal liver cells. These results confirmed previous reports $[28,29]$ that some NO donating derivatives showed less cytotoxicity to normal cells.

Table 2. Antiproliferative activity of the synthesized compounds $\left(\mathrm{IC}_{50} \mu \mathrm{M}\right)$.

\begin{tabular}{ccccccc}
\hline Compound & K562 & MGC-803 & CaEs-17 & Bel-7402 & L-02 & SI $^{\mathbf{2}}$ \\
\hline $\mathbf{7}$ & $4.76 \pm 0.32$ & $5.69 \pm 0.39$ & $11.03 \pm 1.02$ & $7.48 \pm 0.53$ & $18.26 \pm 0.81$ & 2.4 \\
$\mathbf{8}$ & $8.11 \pm 0.76$ & $14.21 \pm 1.22$ & $30.84 \pm 2.09$ & $32.96 \pm 2.19$ & $24.37 \pm 1.59$ & 0.7 \\
$\mathbf{9 a}$ & $2.47 \pm 0.16$ & $1.83 \pm 0.16$ & $5.12 \pm 0.42$ & $1.33 \pm 0.10$ & $10.36 \pm 0.61$ & 7.7 \\
$\mathbf{9 b}$ & $2.31 \pm 0.21$ & $1.62 \pm 0.08$ & $4.83 \pm 0.30$ & $1.20 \pm 0.08$ & $16.73 \pm 0.17$ & 13.9 \\
$\mathbf{9 c}$ & $1.93 \pm 0.10$ & $1.34 \pm 0.13$ & $3.76 \pm 0.37$ & $0.83 \pm 0.06$ & $19.87 \pm 0.18$ & 23.9 \\
$\mathbf{9 d}$ & $2.15 \pm 0.12$ & $1.50 \pm 0.10$ & $4.98 \pm 0.42$ & $1.23 \pm 0.08$ & $13.58 \pm 1.31$ & 11.0 \\
$\mathbf{9 e}$ & $1.92 \pm 0.09$ & $1.29 \pm 0.12$ & $4.27 \pm 0.35$ & $0.92 \pm 0.05$ & $17.20 \pm 0.77$ & 18.6 \\
$\mathbf{9 f}$ & $1.68 \pm 0.12$ & $1.11 \pm 0.05$ & $3.60 \pm 0.12$ & $0.72 \pm 0.04$ & $18.80 \pm 1.25$ & 26.1 \\
$\mathbf{9 g}$ & $2.26 \pm 0.08$ & $1.43 \pm 0.08$ & $5.13 \pm 0.22$ & $1.27 \pm 0.11$ & $11.57 \pm 0.39$ & 9.1 \\
$\mathbf{9 h}$ & $2.11 \pm 0.16$ & $1.49 \pm 0.11$ & $4.68 \pm 0.31$ & $1.08 \pm 0.05$ & $12.09 \pm 1.08$ & 11.1 \\
$\mathbf{9 i}$ & $1.86 \pm 0.18$ & $1.25 \pm 0.10$ & $3.82 \pm 0.19$ & $0.78 \pm 0.04$ & $14.57 \pm 0.86$ & 18.6 \\
Taxol $^{\mathbf{1}}$ & $0.41 \pm 0.02$ & $0.85 \pm 0.06$ & $0.43 \pm 0.03$ & $1.89 \pm 0.09$ & $3.73 \pm 0.17$ & 1.9 \\
\hline
\end{tabular}

${ }^{1}$ Taxol was used a positive control. Data were means \pm SD of three experiments; ${ }^{2}$ SI: selectivity index. It was calculated as: $\mathrm{SI}=\mathrm{IC}_{50, \mathrm{~L}-02} / \mathrm{IC}_{50, \text { Bel-7402 }}$.

In most cases against the selected tumor cell lines, among the derivatives $9 \mathbf{a}-\mathbf{i}$, when the substitution $\mathrm{R}_{1}$ was the same $(\mathbf{9} \mathbf{a}-\mathbf{c}, \mathbf{9} \mathbf{d}-\mathbf{f}$ and $\mathbf{9 g}-\mathbf{i})$ and $\mathrm{R}_{2}$ was changed among $\left(\mathrm{CH}_{2}\right)_{2},\left(\mathrm{CH}_{2}\right)_{3}$, and $o-\mathrm{C}_{6} \mathrm{H}_{4}$ in each group, compounds $(9 \mathrm{c}, 9 \mathrm{f}$ and $9 \mathbf{i})$ with $\mathrm{R}_{2}$ of aromatic group of $o-\mathrm{C}_{6} \mathrm{H}_{4}$ showed stronger activity than corresponding ones with alkyl groups $(\mathbf{9 a}, \mathbf{9 b}, \mathbf{9 d}, \mathbf{9 e}, \mathbf{9 g}$ and $\mathbf{9 h})$. Between alkyl substituents $\left(\mathrm{CH}_{2}\right)_{2}$ and $\left(\mathrm{CH}_{2}\right)_{3}$ in $\mathrm{R}_{2}$, the latter one $(\mathbf{9 b}, \mathbf{9 e}$ and $\mathbf{9 h})$ was favorable. For example, $\mathbf{9 i}$ with the same $\mathrm{R}_{1}$ of $\left(\mathrm{CH}_{2}\right)_{4}$ as $9 \mathrm{~g}$ and $9 \mathbf{h}$, and $\mathrm{R}_{2}$ of $o-\mathrm{C}_{6} \mathrm{H}_{4}$, showed slightly lower $\mathrm{IC}_{50}$ values of $1.25,1.86$, 3.82 and $0.78 \mu \mathrm{M}$ against K562, MGC-803, CaEs-17 and Bel-7402 tumor cells, respectively. When the substitution $\mathrm{R}_{2}$ was the same and $\mathrm{R}_{1}$ was changed among $\left(\mathrm{CH}_{2}\right)_{2},\left(\mathrm{CH}_{2}\right)_{3}$, and $\left(\mathrm{CH}_{2}\right)_{4}$, compounds showed statistically equal $\mathrm{IC}_{50}$ values.

\subsection{NO-Releasing Ability}

The NO-releasing ability of $\mathbf{9 a}-\mathbf{i}$ was determined by Griess assay at $100 \mu \mathrm{M}$ and measured at the time point of 10, 20, 30, 40, 50 and $60 \mathrm{~min}$ (Figure 1). The concentrations of released NO for all synthetic hybrids increased with time and were more than $20 \mu \mathrm{mol} / \mathrm{L}$ (except 9c) at the time point of $60 \mathrm{~min}$. High NO releasing ability might, at least to a certain extent, contribute to antiproliferative and antibacterial activities $[23,26]$. The most promising NO-releasing enmein-type 6,7-seco-ent-kauranoid derivative was $9 \mathrm{f}$ with the highest selectivity index (SI) value of 26.1. It was chosen for intensive mechanism study on hepatoma Bel-7402 cell line. 


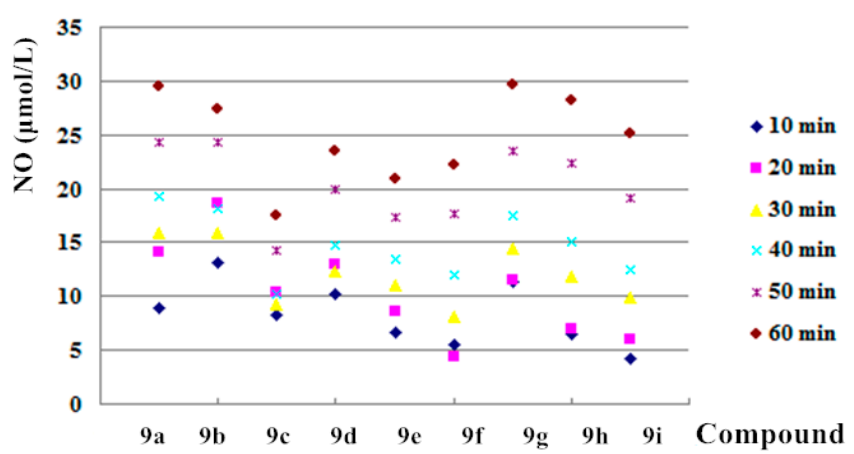

Figure 1. NO-releasing ability of compounds $9 \mathbf{a}-\mathbf{i}$.

\subsection{Influence of 9 f on the Bel-7402 Cell Cycle}

Cell cycle arrest is an important sign for inhibition of proliferation and the series of events that take place in a cell leading to its division and replication. Some NO donating hybrids exhibited cell cycle arrest properties [28]. As the inhibitory effect of 9 f on cell proliferation was observed, we next assessed the effect on the cell cycle distribution of Bel-7402 cells by flow cytometry (Figure 2). Treatment of Bel-7402 cells with 9f at $0.25,0.5$ and $1 \mu \mathrm{M}$ resulted in a remarkable increase in the percentage of cells in $\mathrm{S} / \mathrm{G}_{2}$ phase from $25.51 \%$ of control group to $31.78 \%, 45.33 \%$, and $49.78 \%$, respectively. Compound $9 \mathrm{f}$ could influence Bel-7402 cell cycle progression at low micromolar concentrations in a dose-dependent manner.
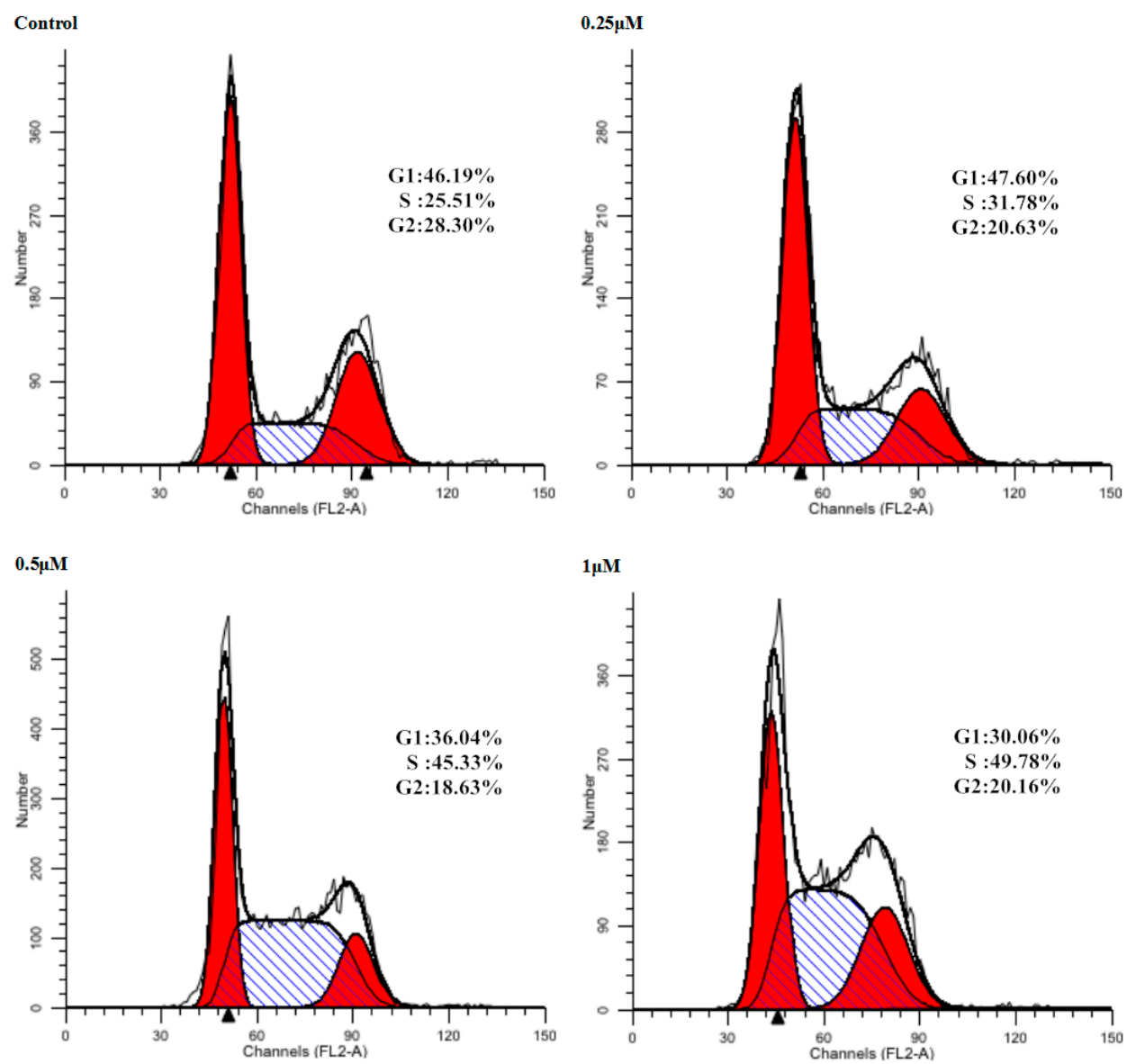

Figure 2. Influence of Bel-7402 cell cycle by $9 f$. Left red part: cells in $\mathrm{G}_{1}$ phase; Right red part: cells in $\mathrm{G}_{2}$ phase; Oblique line part: cells in S phase; White part: total cells. 


\subsection{Induction of Apoptosis by $\mathbf{9 f}$}

To examine the potent cancer cell antiproliferative effect of 9f on Bel-7402 cells, the number of apoptotic cells was monitored using flow cytometry. The total percentage of apoptotic cells (early and late, Q2 + Q4) was 7.88\% treated with a vehicle alone. In comparison with the control group, 2.76-, 4.54-, and 8.01-fold percentages of apoptotic cells were observed when different concentrations $(0.25,0.5$ and $1 \mu \mathrm{M}$ ) of 9 f were added to Bel-7402 cells. As shown in Figure 3, compound 9 f caused significant induction of apoptosis in a dose-dependent manner in Bel-7402 cells and resulted in 21.74\%, 35.78\% and $63.15 \%$ apoptotic cells, respectively.

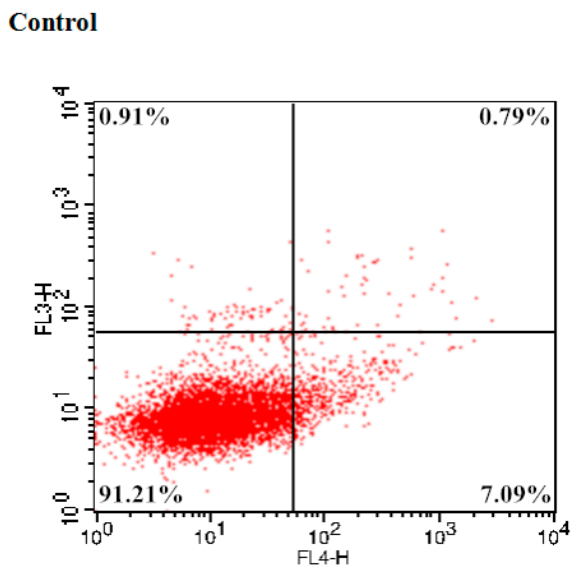

$0.25 \mu \mathrm{M}$
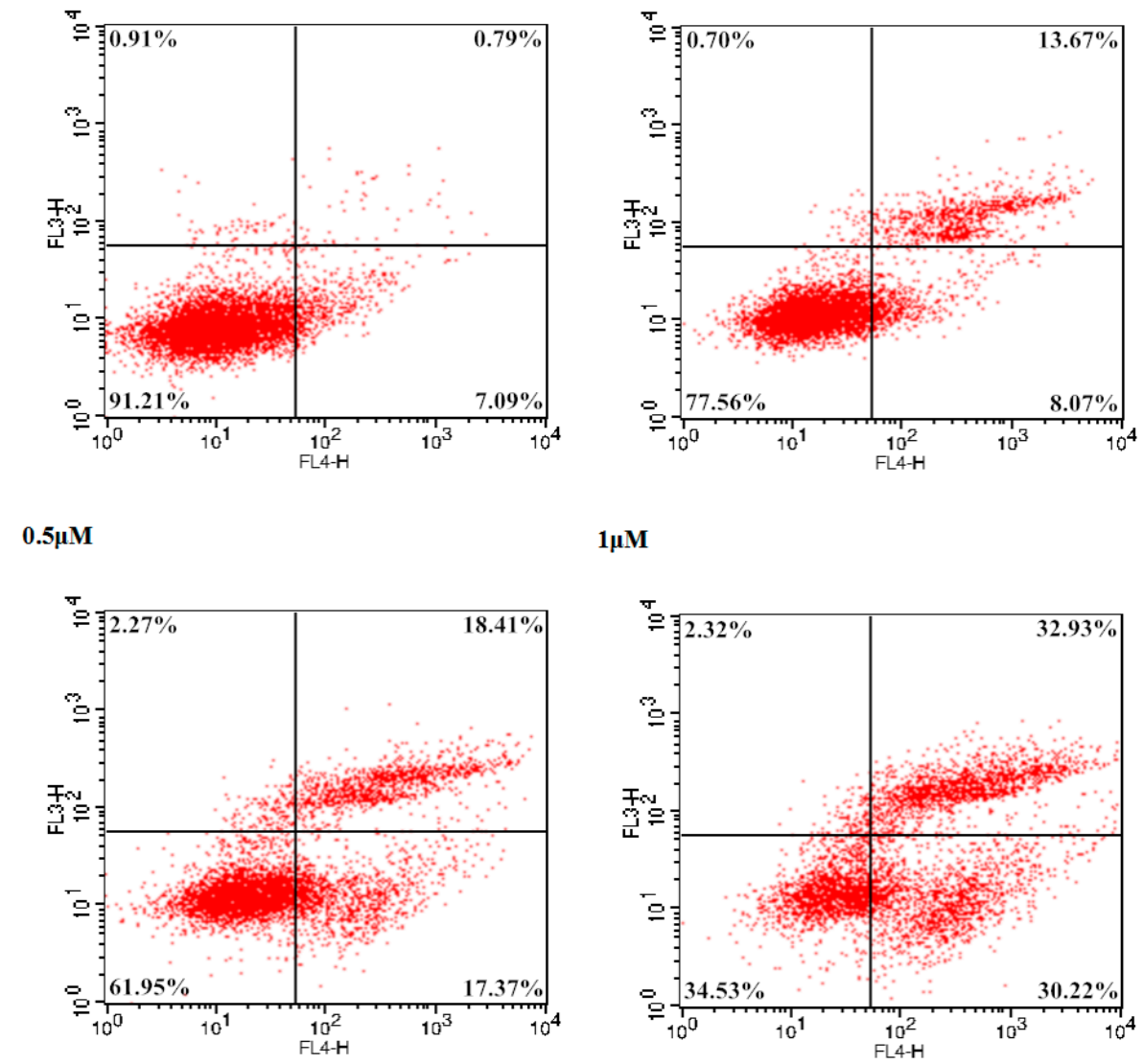

$1 \mu \mathrm{M}$

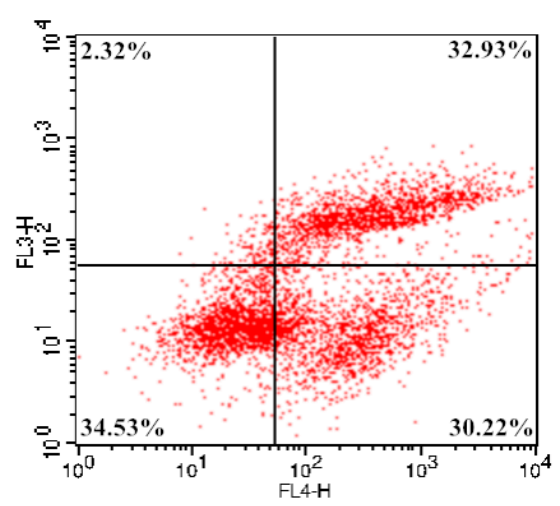

Figure 3. Induction of apoptosis by $9 \mathrm{f}$ in Bel-7402 cells.

\section{7. $9 f$ Induced Mitochondrial Depolarization}

In the field of cancer, cellular apoptosis plays a very important role. The loss of mitochondrial membrane potential is a key event during drug-induced apoptosis. In order to investigate the mitochondria related effect of 9f, the fluorescent probe JC-1 (Keygen, KGA601, Nanjing, China) was used to detect the changes on mitochondrial membrane potential. Before Bel-7402 cells were stained with JC-1, cells were incubated with $0,0.15,0.3$, and $0.6 \mu \mathrm{M}$ of $9 \mathrm{f}$. Then, the flow cytometry analysis was carried out to determine the cell numbers with collapsed mitochondria in different cell groups (Figure 4). The percentage of apoptotic cells increased in a dose-dependent fashion and showed $4.62 \%, 8.81 \%, 21.82 \%$ and $25.98 \%$, respectively. These results together with Annexin-V and PI double stain apoptosis assay confirmed that 9f could induce apoptosis in a Bel-7402 cells mitochondria-related pathway. 
Control

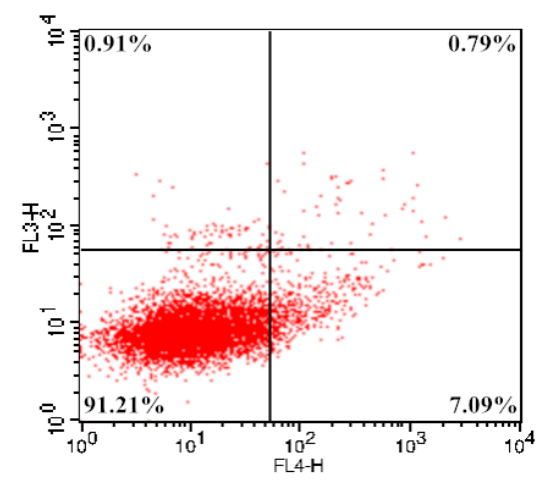

$0.5 \mu \mathrm{M}$

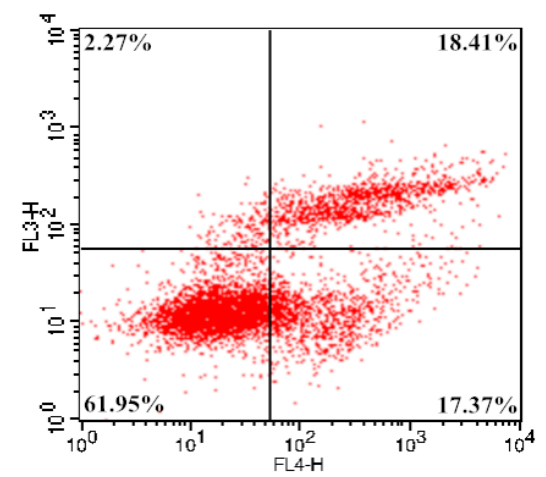

$0.25 \mu \mathrm{M}$

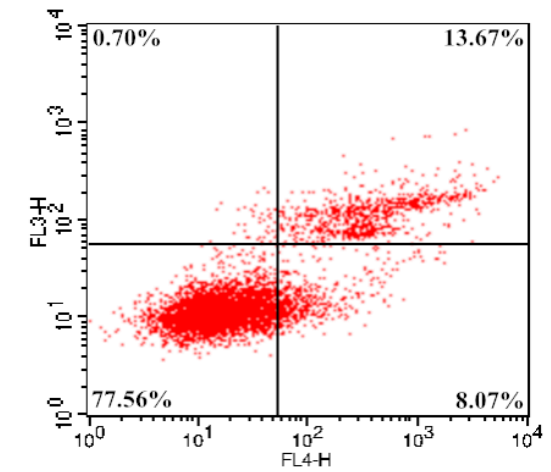

$1 \mu \mathrm{M}$

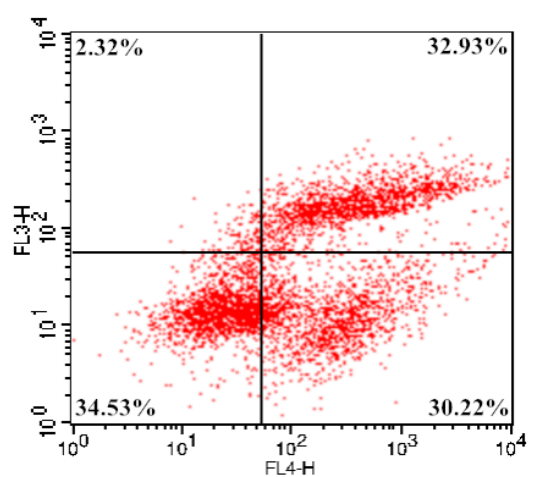

Figure 4. 9f induced mitochondrial depolarization in Bel-7402 cells.

\section{Materials and Methods}

\subsection{Chemistry}

\subsubsection{General}

All commercially available solvents and reagents were purchased from a local commercial supplier (Yuwang Chemical Industries, Ltd., Shenyang, China) and used directly. Melting points (m.p.) were tested using micro melting point apparatus XT-4 (Taike, Beijing, China) and not corrected. Infrared (IR) spectra were recorded on a Nicolet Impact 410 instrument (Thermo Fisher Scientific, Waltham, MA, USA) using a $\mathrm{KBr}$ pellet. ${ }^{1} \mathrm{H}$ and ${ }^{13} \mathrm{C}$ NMR spectra were taken (TMS as internal standard) on a Bruker AV-300 (Bruker Corp., Karlsruhe, Germany) or ACF 500 spectrometer (Bruker Corp., Karlsruhe, Germany) in $\mathrm{CDCl}_{3}$. Low resolution mass spectra (MS) were carried out using FTMS-2000 (Thermo Fisher Scientific, Waltham, MA, USA). High resolution mass spectra (HR-MS) were obtained with Agilent QTOF 6520 (Agilent Technologies China, Beijing, China).

\subsubsection{General Procedure to Synthesize $9 \mathbf{a}-\mathbf{i}$}

Compound 8 (72 mg, $0.2 \mathrm{mmol})$ was dissolved in $15 \mathrm{~mL}$ of dichloromethane and mixed with $6 \mathbf{6}-\mathbf{i}$ $(0.24 \mathrm{mmol})$, EDCI and DMAP, stirring at room temperature for $8 \mathrm{~h}$. When the reaction was finished (monitored by TLC), the reaction mixture was poured into $10 \% \mathrm{HCl}$ (about $15 \mathrm{~mL}$ ), and then extracted three times (each $10 \mathrm{~mL}$ ) with dichloromethane. The organic phases were combined together, washed with water (about $15 \mathrm{~mL}$ ) and saturated brine (about $15 \mathrm{~mL}$ ), sequentially, then dried over anhydrous $\mathrm{Na}_{2} \mathrm{SO}_{4}$, and evaporated to dryness in reduced pressure. At the last step, the product was purified by flash column chromatography $\left(\mathrm{CH}_{2} \mathrm{Cl}_{2} / \mathrm{MeOH} v / v 300: 1\right)$ to obtain the target molecules. 
Compound 9a: white solid, 48\% yield: m.p. $92{ }^{\circ} \mathrm{C}-94{ }^{\circ} \mathrm{C}$; $\mathrm{IR}(\mathrm{KBr}) v_{\max } 3439,2959,2025,1723,1615$, 1553, 1450, 1371, 734, $685 \mathrm{~cm}^{-1} ;{ }^{13} \mathrm{C} \mathrm{NMR}\left(\mathrm{CDCl}_{3}, 100 \mathrm{MHz}\right), \delta$ (ppm) 198.07, 172.91, 172.69, 167.22, $158.99,147.86,138.18,135.83,129.89(\times 2), 128.68(\times 2), 120.53,110.61,101.90,76.18,74.67,74.09,68.13$, $61.46,60.34,53.93,49.96,48.60,40.77,37.16,33.12,33.03,31.72,31.13,29.89,23.33,23.16,19.74 ;{ }^{1} \mathrm{H}$ NMR $\left(\mathrm{CDCl}_{3}, 300 \mathrm{MHz}\right), \delta(\mathrm{ppm}) 8.07\left(2 \mathrm{H}, \mathrm{d}, J=7.5 \mathrm{~Hz}, 2^{\prime}, 6^{\prime}-\mathrm{Ar}-\mathrm{H}\right), 7.78\left(1 \mathrm{H}, \mathrm{d}, J=7.5 \mathrm{~Hz}, 4^{\prime}-\mathrm{Ar}-\mathrm{H}\right), 7.64$ $\left(2 \mathrm{H}, \mathrm{t}, J=7.5 \mathrm{~Hz}, 3^{\prime}, 5^{\prime}-\mathrm{Ar}-\mathrm{H}\right), 6.20(1 \mathrm{H}, \mathrm{s}, 6-\mathrm{OH}), 5.74\left(1 \mathrm{H}, \mathrm{s}, 17-\mathrm{CH}_{2}\right), 5.62\left(1 \mathrm{H}, \mathrm{s}, 17-\mathrm{CH}_{2}\right), 5.32(1 \mathrm{H}, \mathrm{s}$, 6-CH), 4.47 4.65 (6H, m, overlapped, 1-CH, 14-CH, 25,26- $\left.\mathrm{CH}_{2}\right), 4.05,3.92\left(\right.$ each $1 \mathrm{H}, \mathrm{dd}, J_{\mathrm{A}}=J_{\mathrm{B}}=9.6 \mathrm{~Hz}$, $\left.20-\mathrm{CH}_{2}\right), 3.16(1 \mathrm{H}, \mathrm{d}, J=9.3 \mathrm{~Hz}, 13-\mathrm{CH}), 2.53 \sim 2.90\left(4 \mathrm{H}, \mathrm{m}, 22,23-\mathrm{CH}_{2}\right), 2.17\left(2 \mathrm{H}, \mathrm{m}, 12-\mathrm{CH}_{2}\right), 1.97(1 \mathrm{H}$, $\mathrm{m}, 5-\mathrm{CH}), 1.61 \sim 1.74\left(5 \mathrm{H}, \mathrm{m}, 3,11-\mathrm{CH}_{2}, 9-\mathrm{CH}\right), 1.45\left(2 \mathrm{H}, \mathrm{m}, 2-\mathrm{CH}_{2}\right), 1.01\left(3 \mathrm{H}, \mathrm{s}, 18-\mathrm{CH}_{3}\right), 0.95(3 \mathrm{H}, \mathrm{s}$, 19- $\mathrm{CH}_{3}$ ); MS (ESI) $m / z: 748.1\left[\mathrm{M}+\mathrm{NH}_{4}\right]^{+}, 731.0\left[\mathrm{M}+\mathrm{H}^{+}, 765.3[\mathrm{M}+\mathrm{Cl}]^{-} ; \mathrm{HR}-\mathrm{MS}\left(\mathrm{ESI}, \mathrm{M}+\mathrm{NH}_{4}\right)\right.$ $m / z$ : calcd for $\mathrm{C}_{34} \mathrm{H}_{42} \mathrm{~N}_{3} \mathrm{O}_{14} \mathrm{~S}: 748.2382$, found: 748.2388 .

Compound 9b: white solid, $46 \%$ yield: m.p. $88^{\circ} \mathrm{C}-89{ }^{\circ} \mathrm{C}$; IR (KBr) $v_{\max } 3442,2954,2025,1746,1618$, $1553,1452,1358,732,685 \mathrm{~cm}^{-1} ;{ }^{13} \mathrm{C} \mathrm{NMR}\left(\mathrm{CDCl}_{3}, 100 \mathrm{MHz}\right), \delta$ (ppm) 198.14, 172.73, 172.65, 167.27, $158.79,147.85,138.12,135.87,129.87(\times 2), 128.71(\times 2), 120.54,110.52,101.87,76.17,74.59,74.12,69.04$, $61.23,60.35,53.90,49.93,48.58,40.73,37.12,33.00(\times 2), 32.89,31.10,29.85,23.29,23.13,19.87,19.61 ;{ }^{1} \mathrm{H}$ $\mathrm{NMR}\left(\mathrm{CDCl}_{3}, 500 \mathrm{M} \mathrm{Hz}\right), \delta(\mathrm{ppm}) 8.00\left(2 \mathrm{H}, \mathrm{d}, J=7.5 \mathrm{~Hz}, 2^{\prime}, 6^{\prime}-\mathrm{Ar}-\mathrm{H}\right), 7.89\left(1 \mathrm{H}, \mathrm{d}, J=7.5 \mathrm{~Hz}, 4^{\prime}-\mathrm{Ar}-\mathrm{H}\right)$, $7.74\left(2 \mathrm{H}, \mathrm{t}, J=7.5 \mathrm{~Hz}, 3^{\prime}, 5^{\prime}-\mathrm{Ar}-\mathrm{H}\right), 6.18(1 \mathrm{H}, \mathrm{s}, 6-\mathrm{OH}), 5.73\left(1 \mathrm{H}, \mathrm{s}, 17-\mathrm{CH}_{2}\right), 5.55\left(1 \mathrm{H}, \mathrm{s}, 17-\mathrm{CH}_{2}\right), 5.31$ $(1 \mathrm{H}, \mathrm{s}, 6-\mathrm{CH}), 4.48 \sim 4.63\left(6 \mathrm{H}, \mathrm{m}, 1-\mathrm{CH}, 14-\mathrm{CH}, 26,27-\mathrm{CH}_{2}\right), 4.05,3.92\left(\right.$ each $1 \mathrm{H}, \mathrm{dd}, J_{\mathrm{A}}=J_{\mathrm{B}}=9.0 \mathrm{~Hz}$, 20- $\left.\mathrm{CH}_{2}\right), 3.14(1 \mathrm{H}, \mathrm{d}, J=9.0 \mathrm{~Hz}, 13-\mathrm{CH}), 2.38 \sim 2.73\left(6 \mathrm{H}, \mathrm{m}\right.$, overlapped, 22,23,24- $\left.\mathrm{CH}_{2}\right), 2.00(2 \mathrm{H}, \mathrm{m}$, 12- $\left.\mathrm{CH}_{2}\right), 1.95(1 \mathrm{H}, \mathrm{m}, 5-\mathrm{CH}), 1.61 \sim 1.74\left(5 \mathrm{H}, \mathrm{m}, 3,11-\mathrm{CH}_{2}, 9-\mathrm{CH}\right), 1.45\left(2 \mathrm{H}, \mathrm{m}, 2-\mathrm{CH}_{2}\right), 1.02(3 \mathrm{H}, \mathrm{s}$, $\left.18-\mathrm{CH}_{3}\right), 0.95\left(3 \mathrm{H}, \mathrm{s}, 19-\mathrm{CH}_{3}\right) ; \mathrm{MS}(\mathrm{ESI}) \mathrm{m} / z: 762.3\left[\mathrm{M}+\mathrm{NH}_{4}\right]^{+}, 745.2[\mathrm{M}+\mathrm{H}]^{+}, 779.4[\mathrm{M}+\mathrm{Cl}]^{-}$; HR-MS (ESI, $\mathrm{M}+\mathrm{NH}_{4}$ ) $m / z$ : calcd for $\mathrm{C}_{35} \mathrm{H}_{44} \mathrm{~N}_{3} \mathrm{O}_{14} \mathrm{~S}$ : 762.2539, found: 762.2532.

Compound 9c: white solid, $45 \%$ yield: m.p. $137^{\circ} \mathrm{C}-139^{\circ} \mathrm{C}$; IR (KBr) $v_{\max } 3443,2954,2025,1757,1727$, 1617, 1553, 1450, 735, $685 \mathrm{~cm}^{-1} ;{ }^{13} \mathrm{C}$ NMR (CDCl $\left.3,100 \mathrm{MHz}\right), \delta$ (ppm) 198.21, 167.15, 167.06, 166.58, 158.87, 147.65, 137.95, 135.74, 131.89, 131.71, 131.19, 130.92, 130.14, $129.76(\times 2), 128.87,128.55(\times 2)$; $120.72,110.49,101.80,76.24,75.27,74.58,68.88,62.45,60.21,53.87,50.14,48.76,40.74,37.00,32.93,30.97$, 31.08, 29.86, 23.29, 23.07, 19.76; ${ }^{1} \mathrm{H}$ NMR $\left(\mathrm{CDCl}_{3}, 300 \mathrm{M} \mathrm{Hz}\right), \delta(\mathrm{ppm}) 8.00\left(2 \mathrm{H}, \mathrm{d}, J=7.5 \mathrm{~Hz}, 2^{\prime}, 6^{\prime}-\mathrm{Ar}-\mathrm{H}\right)$, $7.81\left(1 \mathrm{H}, \mathrm{t}, J=4.5 \mathrm{~Hz}, 4^{\prime}-\mathrm{Ar}-\mathrm{H}\right), 7.69(1 \mathrm{H}, \mathrm{t}, J=4.5 \mathrm{~Hz}, 22-\mathrm{Ar}-\mathrm{H}), 7.56(3 \mathrm{H}, \mathrm{m}, 21,23,24-\mathrm{Ar}-\mathrm{H}), 7.41$ $\left(2 \mathrm{H}, \mathrm{t}, J=7.5 \mathrm{~Hz}, 3^{\prime}, 5^{\prime}-\mathrm{Ar}-\mathrm{H}\right), 6.24(1 \mathrm{H}, \mathrm{s}, 6-\mathrm{OH}), 5.87\left(1 \mathrm{H}, \mathrm{s}, 17-\mathrm{CH}_{2}\right), 5.52\left(1 \mathrm{H}, \mathrm{s}, 17-\mathrm{CH}_{2}\right), 5.33(1 \mathrm{H}, \mathrm{s}$, 6-CH), 4.40 4.76 (6H, m, 1-CH, 14-CH, 29,30- $\left.\mathrm{CH}_{2}\right), 4.07,3.96$ (each $1 \mathrm{H}, \mathrm{dd}, J_{\mathrm{A}}=J_{\mathrm{B}}=9.3 \mathrm{~Hz}, 20-\mathrm{CH}_{2}$ ), $3.29(1 \mathrm{H}, \mathrm{d}, J=9.6 \mathrm{~Hz}, 13-\mathrm{CH}), 2.17\left(2 \mathrm{H}, \mathrm{m}, 12-\mathrm{CH}_{2}\right), 1.97(1 \mathrm{H}, \mathrm{m}, 5-\mathrm{CH}), 1.52 \sim 1.80\left(5 \mathrm{H}, \mathrm{m}, 3,11-\mathrm{CH}_{2}\right.$, 9-CH), $1.41\left(2 \mathrm{H}, \mathrm{m}, 2-\mathrm{CH}_{2}\right), 1.02\left(3 \mathrm{H}, \mathrm{s}, 18-\mathrm{CH}_{3}\right), 0.98\left(3 \mathrm{H}, \mathrm{s}, 19-\mathrm{CH}_{3}\right)$; MS (ESI) $\mathrm{m} / \mathrm{z}: 801.3[\mathrm{M}+\mathrm{Na}]^{+}$; HR-MS (ESI, $\mathrm{M}+\mathrm{NH}_{4}$ ) $m / z$ : calcd for $\mathrm{C}_{38} \mathrm{H}_{42} \mathrm{~N}_{3} \mathrm{O}_{14} \mathrm{~S}: 796.2382$, found: 796.2376.

Compound 9d: white solid, $44 \%$ yield: m.p. $110{ }^{\circ} \mathrm{C}-112{ }^{\circ} \mathrm{C}$; IR (KBr) $v_{\max } 3459,2955,2025,1754,1615$, $1554,1451,1355,732,685 \mathrm{~cm}^{-1} ;{ }^{13} \mathrm{C} \mathrm{NMR}\left(\mathrm{CDCl}_{3}, 100 \mathrm{MHz}\right), \delta$ (ppm) 197.92, 172.08, 171.73, 167.13, 158.90, 147.69, 138.01, 135.67, $129.73(\times 2), 128.60(\times 2) ; 120.46,110.56,101.76,76.04,74.52,74.18,67.91$, $60.35,60.16,53.79,49.79,48.47,40.59,36.98,32.88,30.99,29.74,29.05,28.65,27.81,23.18,23.03,19.70 ;{ }^{1} \mathrm{H}$ NMR $\left(\mathrm{CDCl}_{3}, 300 \mathrm{M} \mathrm{Hz}\right), \delta(\mathrm{ppm}) 8.03\left(2 \mathrm{H}, \mathrm{d}, J=9.0 \mathrm{~Hz}, 2^{\prime}, 6^{\prime}-\mathrm{Ar}-\mathrm{H}\right), 7.91\left(1 \mathrm{H}, \mathrm{t}, J=8.1 \mathrm{~Hz}, 4^{\prime}-\mathrm{Ar}-\mathrm{H}\right)$, $7.75\left(2 \mathrm{H}, \mathrm{t}, J=9.0 \mathrm{~Hz}, 3^{\prime}, 5^{\prime}-\mathrm{Ar}-\mathrm{H}\right), 6.04(1 \mathrm{H}, \mathrm{s}, 6-\mathrm{OH}), 5.74\left(1 \mathrm{H}, \mathrm{s}, 17-\mathrm{CH}_{2}\right), 5.69\left(1 \mathrm{H}, \mathrm{s}, 17-\mathrm{CH}_{2}\right), 5.19$ $(1 \mathrm{H}, \mathrm{s}, 6-\mathrm{CH}), 4.68(2 \mathrm{H}, \mathrm{m}, 1,14-\mathrm{CH}), 4.45\left(2 \mathrm{H}, \mathrm{t}, J=6.0 \mathrm{~Hz}, 25-\mathrm{CH}_{2}\right), 4.14\left(2 \mathrm{H}, \mathrm{t}, J=6.0 \mathrm{~Hz}, 27-\mathrm{CH}_{2}\right)$, $3.90,3.54\left(\right.$ each $\left.1 \mathrm{H}, \mathrm{dd}, J_{\mathrm{A}}=J_{\mathrm{B}}=9.0 \mathrm{~Hz}, 20-\mathrm{CH}_{2}\right), 3.14(1 \mathrm{H}, \mathrm{d}, J=5.4 \mathrm{~Hz}, 13-\mathrm{CH}), 2.36 \sim 2.63(6 \mathrm{H}, \mathrm{m}$, 22,23,26- $\left.-\mathrm{CH}_{2}\right), 2.08\left(2 \mathrm{H}, \mathrm{m}, 12-\mathrm{CH}_{2}\right), 1.38 \sim 1.76\left(6 \mathrm{H}, \mathrm{m}, 3,11-\mathrm{CH}_{2}, 5,9-\mathrm{CH}\right), 1.43\left(2 \mathrm{H}, \mathrm{m}, 2-\mathrm{CH}_{2}\right), 0.93$ $\left(3 \mathrm{H}, \mathrm{s}, 18-\mathrm{CH}_{3}\right), 0.85\left(3 \mathrm{H}, \mathrm{s}, 19-\mathrm{CH}_{3}\right)$; MS (ESI) $m / z: 767.3[\mathrm{M}+\mathrm{Na}]^{+}$; HR-MS (ESI, $\left.\mathrm{M}+\mathrm{NH}_{4}\right) \mathrm{m} / z$ : calcd for $\mathrm{C}_{35} \mathrm{H}_{44} \mathrm{~N}_{3} \mathrm{O}_{14} \mathrm{~S}: 762.2539$, found: 762.2551.

Compound 9e: white solid, $42 \%$ yield: m.p. $82{ }^{\circ} \mathrm{C}-84{ }^{\circ} \mathrm{C}$; IR (KBr) $v_{\max } 3458,2955,2025,1738,1615$, $1554,1451,1358,732,685 \mathrm{~cm}^{-1}$; ${ }^{13} \mathrm{C} \mathrm{NMR}\left(\mathrm{CDCl}_{3}, 100 \mathrm{MHz}\right), \delta$ (ppm) 197.96, 172.78, 172.56, 167.11, $158.85,147.73,138.02,135.71,129.76(\times 2), 128.53(\times 2), 120.40,110.47,101.75,76.05,74.49,73.96,68.00$, $61.33,60.16,53.79,49.82,48.46,40.63,37.01,32.97,32.89,31.57,30.99,29.74,27.88,23.19,23.03,19.75$, 
19.60; ${ }^{1} \mathrm{H} \mathrm{NMR}\left(\mathrm{CDCl}_{3}, 300 \mathrm{M} \mathrm{Hz}\right), \delta(\mathrm{ppm}) 8.02\left(2 \mathrm{H}, \mathrm{d}, J=8.4 \mathrm{~Hz}, 2^{\prime}, 6^{\prime}-\mathrm{Ar}-\mathrm{H}\right), 7.90(1 \mathrm{H}, \mathrm{t}, J=7.5 \mathrm{~Hz}$, $\left.4^{\prime}-\mathrm{Ar}-\mathrm{H}\right), 7.74\left(2 \mathrm{H}, \mathrm{t}, J=8.4 \mathrm{~Hz}, 3^{\prime}, 5^{\prime}-\mathrm{Ar}-\mathrm{H}\right), 6.25(1 \mathrm{H}, \mathrm{d}, J=2.2 \mathrm{~Hz}, 6-\mathrm{OH}), 6.01\left(1 \mathrm{H}, \mathrm{s}, 17-\mathrm{CH}_{2}\right), 5.77$ $(1 \mathrm{H}, \mathrm{s}, 14-\mathrm{CH}), 5.68\left(1 \mathrm{H}, \mathrm{s}, 17-\mathrm{CH}_{2}\right), 5.19(1 \mathrm{H}, \mathrm{d}, J=2.4 \mathrm{~Hz}, 6-\mathrm{CH}), 4.71(1 \mathrm{H}, \mathrm{m}, 1-\mathrm{CH}), 4.55(2 \mathrm{H}, \mathrm{t}$, $\left.J=6.0 \mathrm{~Hz}, 26-\mathrm{CH}_{2}\right), 4.12\left(2 \mathrm{H}, \mathrm{t}, J=6.0 \mathrm{~Hz}, 28-\mathrm{CH}_{2}\right), 3.88,3.35\left(\right.$ each $\left.1 \mathrm{H}, \mathrm{dd}, J_{\mathrm{A}}=J_{\mathrm{B}}=9.0 \mathrm{~Hz}, 20-\mathrm{CH}_{2}\right)$, $3.17(1 \mathrm{H}, \mathrm{d}, J=9.3 \mathrm{~Hz}, 13-\mathrm{CH}), 2.21 \sim 2.51\left(8 \mathrm{H}, \mathrm{m}\right.$, overlapped, 22,23,24,27- $\left.\mathrm{CH}_{2}\right), 2.07\left(2 \mathrm{H}, \mathrm{m}, 12-\mathrm{CH}_{2}\right)$, 1.67 1.78 (6H, m, overlapped, 3,11- $\left.\mathrm{CH}_{2}, 5,9-\mathrm{CH}\right), 1.24\left(2 \mathrm{H}, \mathrm{m}, 2-\mathrm{CH}_{2}\right), 0.94\left(3 \mathrm{H}, \mathrm{s}, 18-\mathrm{CH}_{3}\right), 0.88(3 \mathrm{H}$, $\mathrm{s}, 19-\mathrm{CH}_{3}$ ); MS (ESI) $m / z: 781.4[\mathrm{M}+\mathrm{Na}]^{+}$; HR-MS (ESI, $\left.\mathrm{M}+\mathrm{NH}_{4}\right) \mathrm{m} / z$ : calcd for $\mathrm{C}_{36} \mathrm{H}_{46} \mathrm{~N}_{3} \mathrm{O}_{14} \mathrm{~S}$ : 776.2695, found: 776.2687 .

Compound 9f: white solid, $28 \%$ yield: m.p. $128{ }^{\circ} \mathrm{C}-130{ }^{\circ} \mathrm{C}$; IR (KBr) $v_{\max } 3445,2956,2025,1758$, $1723,1616,1554,1451,735,685 \mathrm{~cm}^{-1} ;{ }^{13} \mathrm{C}$ NMR $\left(\mathrm{CDCl}_{3}, 100 \mathrm{MHz}\right), \delta(\mathrm{ppm}) 198.23,167.13,167.02$, 166.55, 158.86, 147.67, 137.94, 135.77, 131.91, 131.67, 131.18, 130.94, 130.15, $129.76(\times 2), 128.85,128.54$ (×2); 120.75, 110.51, 101.84, 76.27, 75.29, 74.54, 68.91, 62.48, 60.23, 53.91, 50.09, 48.78, 40.72, 37.02, $32.97,30.99,31.07,29.86,29.79,23.30,23.12,19.75 ;{ }^{1} \mathrm{H}$ NMR $\left(\mathrm{CDCl}_{3}, 300 \mathrm{M} \mathrm{Hz}\right), \delta(\mathrm{ppm}) 8.07(2 \mathrm{H}, \mathrm{d}$, $\left.J=7.0 \mathrm{~Hz}, 2^{\prime}, 6^{\prime}-\mathrm{Ar}-\mathrm{H}\right), 7.75\left(2 \mathrm{H}, \mathrm{m}, 22,4^{\prime}-\mathrm{Ar}-\mathrm{H}\right), 7.64(3 \mathrm{H}, \mathrm{m}, 21,23,24-\mathrm{Ar}-\mathrm{H}), 7.57\left(2 \mathrm{H}, \mathrm{m}, 3^{\prime}, 5^{\prime}-\mathrm{Ar}-\mathrm{H}\right)$, $6.21(1 \mathrm{H}, \mathrm{s}, 6-\mathrm{OH}), 5.92\left(1 \mathrm{H}, \mathrm{s}, 17-\mathrm{CH}_{2}\right), 5.56\left(1 \mathrm{H}, \mathrm{s}, 17-\mathrm{CH}_{2}\right), 5.32(1 \mathrm{H}, \mathrm{s}, 6-\mathrm{CH}), 4.31 \sim 4.60(6 \mathrm{H}, \mathrm{m}$, overlapped, 1-CH, 14-CH, 29,31- $\left.\mathrm{CH}_{2}\right), 4.08,3.97$ (each $\left.1 \mathrm{H}, \mathrm{dd}, J_{\mathrm{A}}=J_{\mathrm{B}}=9.0 \mathrm{~Hz}, 20-\mathrm{CH}_{2}\right), 3.26(1 \mathrm{H}, \mathrm{d}$, $J=8.7 \mathrm{~Hz}, 13-\mathrm{CH}), 2.57 \sim 2.78\left(2 \mathrm{H}, \mathrm{m}, 30-\mathrm{CH}_{2}\right), 2.35\left(2 \mathrm{H}, \mathrm{m}, 12-\mathrm{CH}_{2}\right), 1.95(1 \mathrm{H}, \mathrm{m}, 5-\mathrm{CH}), 1.42 \sim 1.78$ $\left(5 \mathrm{H}, \mathrm{m}, 3,11-\mathrm{CH}_{2}, 9-\mathrm{CH}\right), 1.24\left(2 \mathrm{H}, \mathrm{m}, 2-\mathrm{CH}_{2}\right), 1.03\left(3 \mathrm{H}, \mathrm{s}, 18-\mathrm{CH}_{3}\right), 0.96\left(3 \mathrm{H}, \mathrm{s}, 19-\mathrm{CH}_{3}\right) ; \mathrm{MS}$ (ESI) $\mathrm{m} / z$ : $815.4[\mathrm{M}+\mathrm{Na}]^{+}$; HR-MS (ESI, $\mathrm{M}+\mathrm{NH}_{4}$ ) $m / z$ : calcd for $\mathrm{C}_{39} \mathrm{H}_{44} \mathrm{~N}_{3} \mathrm{O}_{14} \mathrm{~S}: 810.2539$, found: 810.2530.

Compound 9g: white solid, $37 \%$ yield: m.p. $85^{\circ} \mathrm{C}-87^{\circ} \mathrm{C}$; IR (KBr) $v_{\max } 3442,2956,2025,1755,1616$, 1554, 1452, 1360, 733, $685 \mathrm{~cm}^{-1} ;{ }^{13} \mathrm{C} \mathrm{NMR}\left(\mathrm{CDCl}_{3}, 100 \mathrm{MHz}\right), \delta$ (ppm) 197.92, 172.21, 172.00, 167.09, $158.93,147.69,138.01,135.67,129.72(\times 2), 128.56(\times 2) ; 120.45,110.47,101.76,76.03,74.55,74.16,70.98$, 63.86, 60.14, 53.78, 49.80, 48.46, 40.59, 36.99, 32.88, 30.99, 29.74, 29.09, 28.74, 25.18, 24.95, 23.19, 23.02, 19.73; ${ }^{1} \mathrm{H} \mathrm{NMR}\left(\mathrm{CDCl}_{3}, 300 \mathrm{M} \mathrm{Hz}\right), \delta(\mathrm{ppm}) 8.06\left(2 \mathrm{H}, \mathrm{d}, J=7.8 \mathrm{~Hz}, 2^{\prime}, 6^{\prime}-\mathrm{Ar}-\mathrm{H}\right), 7.90(1 \mathrm{H}, \mathrm{t}, J=7.2 \mathrm{~Hz}$, $\left.4^{\prime}-\mathrm{Ar}-\mathrm{H}\right), 7.65\left(2 \mathrm{H}, \mathrm{t}, J=7.8 \mathrm{~Hz}, 3^{\prime}, 5^{\prime}-\mathrm{Ar}-\mathrm{H}\right), 6.25(1 \mathrm{H}, \mathrm{s}, 6-\mathrm{OH}), 6.03\left(1 \mathrm{H}, \mathrm{s}, 17-\mathrm{CH}_{2}\right), 5.77(1 \mathrm{H}, \mathrm{s}$, 14-CH), $5.68\left(1 \mathrm{H}, \mathrm{s}, 17-\mathrm{CH}_{2}\right), 5.19(1 \mathrm{H}, \mathrm{s}, 6-\mathrm{CH}), 4.62(1 \mathrm{H}, \mathrm{m}, 1-\mathrm{CH}), 4.42\left(2 \mathrm{H}, \mathrm{m}, 25-\mathrm{CH}_{2}\right), 4.07(2 \mathrm{H}, \mathrm{m}$, $\left.28-\mathrm{CH}_{2}\right), 3.90,3.54\left(\right.$ each $\left.1 \mathrm{H}, \mathrm{dd}, J_{\mathrm{A}}=J_{\mathrm{B}}=10.5 \mathrm{~Hz}, 20-\mathrm{CH}_{2}\right), 3.14(1 \mathrm{H}, \mathrm{d}, J=9.6 \mathrm{~Hz}, 13-\mathrm{CH}), 2.47 \sim 2.54$ (8H, m, overlapped, 22,23,26,27- $\left.\mathrm{CH}_{2}\right), 1.66 \sim 1.81\left(8 \mathrm{H}\right.$, m, overlapped, 3,11,12- $\left.\mathrm{CH}_{2}, 5,9-\mathrm{CH}\right), 1.24(2 \mathrm{H}, \mathrm{m}$, 2- $\left.\mathrm{CH}_{2}\right), 0.93\left(3 \mathrm{H}, \mathrm{s}, 18-\mathrm{CH}_{3}\right), 0.88\left(3 \mathrm{H}, \mathrm{s}, 19-\mathrm{CH}_{3}\right) ; \mathrm{MS}(\mathrm{ESI}) \mathrm{m} / z: 776.3\left[\mathrm{M}+\mathrm{NH}_{4}\right]^{+}, 793.2[\mathrm{M}+\mathrm{Cl}]^{-}$; HR-MS (ESI, $\mathrm{M}+\mathrm{NH}_{4}$ ) $\mathrm{m} / z$ : calcd for $\mathrm{C}_{36} \mathrm{H}_{46} \mathrm{~N}_{3} \mathrm{O}_{14} \mathrm{~S}:$ 776.2695, found: 776.2693.

Compound 9h: white solid, $42 \%$ yield: m.p. $78^{\circ} \mathrm{C}-80{ }^{\circ} \mathrm{C}$; IR (KBr) $v_{\max } 3444,2960,2025,1755,1616$, $1554,1452,1365,732,685 \mathrm{~cm}^{-1} ;{ }^{13} \mathrm{C} \mathrm{NMR}\left(\mathrm{CDCl}_{3}, 100 \mathrm{MHz}\right), \delta$ (ppm) 198.10, 172.34, 172.11, 167.26, 159.04, 147.69, 138.16, 135.81, $129.85(\times 2), 128.66(\times 2) ; 120.58,110.58,101.85,76.18,74.57,74.30,71.11$, $63.98,60.28,53.90,49.92,48.57,40.71,37.09,32.98,31.09,29.84,29.20,28.86,25.29,25.05,23.30,23.13$, 22.76, 19.83; ${ }^{1} \mathrm{H}$ NMR $\left(\mathrm{CDCl}_{3}, 300 \mathrm{M} \mathrm{Hz}\right), \delta(\mathrm{ppm}) 8.06\left(2 \mathrm{H}, \mathrm{d}, J=7.2 \mathrm{~Hz}, 2^{\prime}, 6^{\prime}-\mathrm{Ar}-\mathrm{H}\right), 7.77(1 \mathrm{H}, \mathrm{t}$, $\left.J=7.2 \mathrm{~Hz}, 4^{\prime}-\mathrm{Ar}-\mathrm{H}\right), 7.63\left(2 \mathrm{H}, \mathrm{t}, J=7.2 \mathrm{~Hz}, 3^{\prime}, 5^{\prime}-\mathrm{Ar}-\mathrm{H}\right), 6.21(1 \mathrm{H}, \mathrm{s}, 6-\mathrm{OH}), 5.73\left(1 \mathrm{H}, \mathrm{s}, 17-\mathrm{CH}_{2}\right), 5.57$ $\left(1 \mathrm{H}, \mathrm{s}, 17-\mathrm{CH}_{2}\right), 5.32(1 \mathrm{H}, \mathrm{m}, 6-\mathrm{CH}), 4.57(2 \mathrm{H}, \mathrm{m}, 1,14-\mathrm{CH}), 4.45\left(2 \mathrm{H}, \mathrm{t}, J=6.3 \mathrm{~Hz}, 26-\mathrm{CH}_{2}\right), 4.14(2 \mathrm{H}$, $\left.\mathrm{t}, J=6.0 \mathrm{~Hz}, 29-\mathrm{CH}_{2}\right), 4.06,3.93\left(\right.$ each $\left.1 \mathrm{H}, \mathrm{dd}, J_{\mathrm{A}}=J_{\mathrm{B}}=9.3 \mathrm{~Hz}, 20-\mathrm{CH}_{2}\right), 3.13(1 \mathrm{H}, \mathrm{d}, J=9.6 \mathrm{~Hz}$, 13-CH), 2.45 2.50 (10H, m, overlapped, 22,23,24,27,28- $\left.\mathrm{CH}_{2}\right), 2.35\left(2 \mathrm{H}, \mathrm{m}, 12-\mathrm{CH}_{2}\right), 1.58 \sim 1.98(6 \mathrm{H}, \mathrm{m}$, overlapped, 3,11- $\left.\mathrm{CH}_{2}, 5,9-\mathrm{CH}\right), 1.24\left(2 \mathrm{H}, \mathrm{m}, 2-\mathrm{CH}_{2}\right), 0.93\left(3 \mathrm{H}, \mathrm{s}, 18-\mathrm{CH}_{3}\right), 0.87\left(3 \mathrm{H}, \mathrm{s}, 19-\mathrm{CH}_{3}\right)$; $\mathrm{MS}$ (ESI) $m / z: 795.4[\mathrm{M}+\mathrm{Na}]^{+}$; HR-MS (ESI, $\mathrm{M}+\mathrm{NH}_{4}$ ) $m / z$ : calcd for $\mathrm{C}_{37} \mathrm{H}_{48} \mathrm{~N}_{3} \mathrm{O}_{14} \mathrm{~S}: 790.2852$, found: 790.2841 .

Compound 9i: white solid, $43 \%$ yield: m.p. $126^{\circ} \mathrm{C}-128^{\circ} \mathrm{C}$; IR (KBr) $v_{\max } 3443,2955,2025,1758,1723$, $1615,1553,1451,734,685 \mathrm{~cm}^{-1} ;{ }^{13} \mathrm{C} \mathrm{NMR}\left(\mathrm{CDCl}_{3}, 100 \mathrm{MHz}\right), \delta$ (ppm) 198.12, 167.09, 166.90, 166.51, $158.96,147.64,137.97,135.72,131.71,131.41,131.22,130.89,130.16,129.75(\times 2), 128.64,128.53(\times 2)$; $120.58,110.49,101.76,76.13,74.98,74.56,70.94,64.72,60.15,53.79,49.97,48.69,40.61,36.97,32.88,31.00$, 29.80, 25.26, 24.95, 23.23, 23.02, 19.76; ${ }^{1} \mathrm{H} \mathrm{NMR}\left(\mathrm{CDCl}_{3}, 300 \mathrm{M} \mathrm{Hz}\right), \delta(\mathrm{ppm}) 8.07(2 \mathrm{H}, \mathrm{d}, J=7.8 \mathrm{~Hz}$, $\left.2^{\prime}, 6^{\prime}-\mathrm{Ar}-\mathrm{H}\right), 7.73(3 \mathrm{H}, \mathrm{m}, 23,25,26-\mathrm{Ar}-\mathrm{H}), 7.60\left(2 \mathrm{H}, \mathrm{m}, 24,4^{\prime}-\mathrm{Ar}-\mathrm{H}\right), 7.50\left(2 \mathrm{H}, \mathrm{t}, J=7.8 \mathrm{~Hz}, 3^{\prime}, 5^{\prime}-\mathrm{Ar}-\mathrm{H}\right)$, $6.21(1 \mathrm{H}, \mathrm{s}, 6-\mathrm{OH}), 5.93\left(1 \mathrm{H}, \mathrm{s}, 17-\mathrm{CH}_{2}\right), 5.56\left(1 \mathrm{H}, \mathrm{s}, 17-\mathrm{CH}_{2}\right), 5.34(1 \mathrm{H}, \mathrm{m}, 6-\mathrm{CH}), 4.68(2 \mathrm{H}, \mathrm{m}, 1,14-\mathrm{CH})$, $4.40 \sim 4.62\left(4 \mathrm{H}, \mathrm{m}, 29,32-\mathrm{CH}_{2}\right), 4.08,3.97\left(\right.$ each $\left.1 \mathrm{H}, \mathrm{dd}, J_{\mathrm{A}}=J_{\mathrm{B}}=9.0 \mathrm{~Hz}, 20-\mathrm{CH}_{2}\right), 3.30(1 \mathrm{H}, \mathrm{d}, J=9.0 \mathrm{~Hz}$, 
13-CH), $2.79\left(2 \mathrm{H}, \mathrm{m}, 30-\mathrm{CH}_{2}\right), 2.62\left(2 \mathrm{H}, \mathrm{m}, 31-\mathrm{CH}_{2}\right), 2.42\left(2 \mathrm{H}, \mathrm{m}, 12-\mathrm{CH}_{2}\right), 2.03(1 \mathrm{H}, \mathrm{m}, 5-\mathrm{CH}), 1.97(1 \mathrm{H}$, $\mathrm{m}, 9-\mathrm{CH}), 1.70 \sim 1.81\left(4 \mathrm{H}, \mathrm{m}, 3,11-\mathrm{CH}_{2}\right), 1.24\left(2 \mathrm{H}, \mathrm{m}, 2-\mathrm{CH}_{2}\right), 1.03\left(3 \mathrm{H}, \mathrm{s}, 18-\mathrm{CH}_{3}\right), 0.96\left(3 \mathrm{H}, \mathrm{s}, 19-\mathrm{CH}_{3}\right)$; MS (ESI) $m / z$ : $829.4[\mathrm{M}+\mathrm{Na}]^{+}$; HR-MS (ESI, $\mathrm{M}+\mathrm{NH}_{4}$ ) $m / z$ : calcd for $\mathrm{C}_{40} \mathrm{H}_{46} \mathrm{~N}_{3} \mathrm{O}_{14} \mathrm{~S}: 824.2695$, found: 824.2697 .

\subsection{Biology}

\subsubsection{Antibacterial Assay}

The minimal inhibitory concentrations (MICs) were carried out by microbroth dilution method described by the Clinical Laboratory Standards Institute [30,31]. A stock solution of all the target compounds was prepared with DMSO-medium (1:2), and then graded quantities of the test compounds were diluted with medium. The specified concentration suspension of fungus and bacterium contained approximately $10^{3}$, and $10^{5} \mathrm{CFU} / \mathrm{mL}$ was added into microtitration plates. The inoculated 96-well plates were incubated at $35^{\circ} \mathrm{C}$ for $18 \mathrm{~h}$. MIC was defined as the lowest concentrations that prevented visible growth of the bacteria.

\subsubsection{MTT Assay}

MTT assay was developed to monitor mammalian cell survival and proliferation in vitro [32]. CaEs-17 cells (K562, Bel-7402 and MGC-803 cells) from American Type Culture Collection (ATCC, Manassas, VA, USA) were cultivated in RPMI-1640 medium supplemented with $5 \%$ fetal bovine serum $(v / v), 100 \mathrm{U} / \mathrm{mL}$ penicillin, and $50 \mathrm{mg} / \mathrm{mL}$ streptomycin. Cells $\left(5 \times 10^{4} \mathrm{cell} / \mathrm{mL}\right)$ at the $\log$ phase of their growth cycle were added to each well of a 96-well plate $(100 \mu \mathrm{L} /$ well $)$ and incubated for $24 \mathrm{~h}$ at $37{ }^{\circ} \mathrm{C}$ in a humidified atmosphere of $5 \% \mathrm{CO}_{2}$. Then, cells were treated with or without test compounds in different concentrations. After $72 \mathrm{~h}, 5 \mathrm{mg} / \mathrm{mL}$ MTT solution ( $20 \mu \mathrm{L}$ per well) was added. Cells were incubated at $37^{\circ} \mathrm{C}$. After $4 \mathrm{~h}$, MTT solution was removed and DMSO was added to each well $(150 \mu \mathrm{L})$. Ten minutes later at room temperature, the optical density (OD) values were measured at the wavelength of $490 \mathrm{~nm}$ on a Microplate Reader NO. 550 (BIO-RAD Instruments Inc., Hercules, CA, USA). In this experiment, $10 \mu \mathrm{g} / \mathrm{mL}$ of Taxol was used as the positive control and $0.1 \%$ DMSO was used as the negative reference.

\subsubsection{Griess Assay}

$\mathrm{NO}$ produced by the compounds was determined by assaying the levels of $\mathrm{NO}_{2}$ using the Griess reagent [33]. The levels of $\mathrm{NO}$ released from $100 \mu \mathrm{M}$ of each compound were tested by nitrate/nitrite in triplicate. The lysates were reacted with Griess reagent $(40 \mathrm{~min})$, centrifugalized (10 $\mathrm{min})$, and then measured at $540 \mathrm{~nm}$. This assay was carried out according to the manufacturer's instructions for 60 min (Beyotime, Nanjing, China).

\subsubsection{Cell Cycle Arrest}

Bel-7402 cells $\left(5.0 \times 10^{3}\right.$ cells/well) were plated in 6-well plates and incubated for $24 \mathrm{~h}$, and then incubated with different concentrations $(0.25,0.5$ and $1 \mu \mathrm{M})$ of $9 \mathrm{f}$ at $37^{\circ} \mathrm{C}$ for $48 \mathrm{~h}$. After $48 \mathrm{~h}$ treatment, cells were treated with 70\% ethanol and RNase, sequentially, and stained with PI [34]. Cellular DNA content was measured by a flow cytometer for cell cycle distribution analysis.

\subsubsection{Cellular Apoptosis}

Bel-7402 cells were incubated with different concentrations $(0.25,0.5$ and $1 \mu \mathrm{M})$ of 9 f for $72 \mathrm{~h}$. Then, Annexin-V and PI double staining was used to detect apoptotic cells to analyze apoptosis according to the manufacturer's instructions by flow cytometry [35].

\subsubsection{Mitochondrial Membrane Potential}

Bel-7402 cells were cultured in six-well plates after treatment with 9 f or vehicles for $48 \mathrm{~h}$. The cells were cells were collected by trypsinization, washed with PBS (Sigma Chemical Co., Shanghai, China) 
and stained according to the manufacturer's instruction (Keygen, KGA601, Nanjing, China) with the lipophilic cationic dye JC-1. The flow cytometry analysis was carried out to monitor the percentage of cells with healthy or collapsed mitochondrial membrane potentials [36].

\title{
4. Conclusions
}

In summary, a series of NO donor/enmein-type diterpenoid derivatives $(\mathbf{9 a}-\mathbf{i})$ were synthesized from relevant commercial available resources. All of the target compounds showed antibacterial activity against Gram-positive bacteria S. aureus and B. subtilis and antiproliferative activity against the K562 leukemia cell line, the MGC-803 gastric cancer cell line, the CaEs-17 esophageal cancer cell line, the Bel-7402 hepatoma cell line, and human normal liver cells L-02 to some extent. It was found that $9 \mathrm{~b}$ and $9 \mathrm{~d}$ with the same total linkage length of five carbons were the most active against $S$. aureus and B. subtilis with MICs of 4 and $2 \mu \mathrm{g} / \mathrm{mL}$, respectively. Compound 9 f displayed $\mathrm{IC}_{50}$ values of $1.68,1.11,3.60$ and $0.72 \mu \mathrm{M}$ against four tested cancer cell lines, respectively, and $18.80 \mu \mathrm{M}$ against normal liver cells L-02. The SI value was 26.1 between L-02 normal liver and Bel-7402 hepatoma cell lines. The preliminary SARs were also concluded based on the obtained biological evaluation data. Furthermore, it was also found that $9 \mathrm{f}$ induced apoptosis via the mitochondria-related pathway and arrested cell cycle of Bel-7402 cells at the S stage. These findings were important to explore new chemical entities with innovative natural scaffolds for the treatment of infection combined with solid tumors.

Supplementary Materials: Supplementary materials can be found at http://www.mdpi.com/1422-0067/17/6/ $747 / \mathrm{s} 1$, including ${ }^{1} \mathrm{H}$ NMR and $\mathrm{H}-\mathrm{H}$ COSY of $8,{ }^{1} \mathrm{H}$ and ${ }^{13} \mathrm{C}$ NMR of methyl ester of $6 \mathbf{a}$, and ${ }^{1} \mathrm{H}$ and ${ }^{13} \mathrm{C}$ NMR of 9 .

Acknowledgments: This work was financially supported by the National Natural Science Foundation of China (81373280, 21502121), the Project Funded by the China Post Doctoral Science Foundation (2015M570258), General Scientific Research Projects of the Department of Education in Liaoning Province (L2014382), the Key Laboratory for the Chemistry and Molecular Engineering of Medicinal Resources (Guangxi Normal University), the Ministry of the Education of China (CMEMR2015-B07), the Jiangsu Key Laboratory of New Drug Research and Clinical Pharmacy (KF-XY-201401) and the Career Development Support Plan for Young and Middle-aged Teachers in Shenyang Pharmaceutical University.

Author Contributions: Dahong Li, Huiming Hua and Jinyi $\mathrm{Xu}$ conceived and designed the experiments; Dahong Li, Tong Han, Shengtao Xu, Tingting Zhou and Keguang Cheng performed the experiments; Dahong Li, Keguang Cheng and Zhanlin Li analyzed the data; Dahong Li, Zhenzhong Wang, Wei Xiao and Jinyi Xu wrote the paper. $\mathrm{Xu} \mathrm{Hu}$ revised the manuscript and did the corresponding experiments according to the reviewers' suggestions.

Conflicts of Interest: The authors declare no conflict of interest.

\section{Abbreviations}

NO
SAR
DMAP
EDCI
rt
THF
SI
MTT
TLC
FBS
TMS
${ }^{1}$ HNMR
TMS
ESI MS
HR-MS
DCM

\author{
Nitric Oxide \\ Structure Activity Relationship \\ 4-Dimethylaminopyridine \\ 1-Ethyl-3-(3-dimethylaminopropyl)carbodiimide Hydrochloride \\ Room Temperature \\ Tetrahydrofuran \\ Selectivity Index \\ 3-(4,5-Dimethylthiazol-2-yl)-2,5-diphenyltetrazolium bromide \\ Thin Layer Chromatograph \\ Fetal Bovine Serum \\ Tetramethylsilane \\ Proton Nuclear Magnetic Resonance \\ Tetramethlysilane \\ Electrospray Ionization-Mass Spectrometry \\ High Resolution Mass Spectrum \\ Dichloromethane
}


$\begin{array}{ll}\text { MIC } & \text { Minimal Inhibitory Concentration } \\ \text { PI } & \text { Propidium Iodide } \\ \text { NT } & \text { Not Test }\end{array}$

\section{References}

1. Pfeltz, R.F.; Wilkinson, B.J. The escalating challenge of vancomycin resistance in Staphylococcus aureus. Curr. Drug Targets Infect. Disord. 2004, 4, 273-294. [CrossRef] [PubMed]

2. Roberts, M.C. Distribution of macrolide, lincosamide, streptogramin, ketolide and oxazolidinone (MLSKO) resistance genes in Gram-negative bacteria. Curr. Drug Targets Infect. Disord. 2004, 4, 207-215. [CrossRef] [PubMed]

3. Hoadley, K.A.; Yau, C.; Wolf, D.M.; Cherniack, A.D.; Tamborero, D.; Ng, S.; Leiserson, M.D.; Niu, B.; McLellan, M.D.; Uzunangelov, V.; et al. Multiplatform analysis of 12 cancer types reveals molecular classification within and across tissues of origin. Cell 2014, 158, 929-944. [CrossRef] [PubMed]

4. Wang, K.B.; Di, Y.T.; Bao, Y.; Yuan, C.M.; Chen, G.; Li, D.H.; Bai, J.; He, H.P.; Hao, X.J.; Pei, Y.H.; et al. Peganumine A, a $\beta$-carboline dimer with a new octacyclic scaffold from Peganum harmala. Org. Lett. 2014, 16, 4028-4031. [CrossRef] [PubMed]

5. Sai, C.M.; Li, D.H.; Xue, C.M.; Wang, K.B.; Hu, P.; Pei, Y.H.; Bai, J.; Jing, Y.K.; Li, Z.L.; Hua, H.M. Two pairs of enantiomeric alkaloid dimers from Macleaya cordata. Org. Lett. 2015, 17, 4102-4105. [CrossRef] [PubMed]

6. Rostom, S.A.; Faidallah, H.M.; Radwan, M.F.; Badr, M.H. Bifunctional ethyl 2-amino-4-methylthiazole5-carboxylate derivatives: Synthesis and in vitro biological evaluation as antimicrobial and anticancer agents. Eur. J. Med. Chem. 2014, 76, 170-181. [CrossRef] [PubMed]

7. Climo, M.W.; Yokoe, D.S.; Warren, D.K.; Perl, T.M.; Bolon, M.; Herwaldt, L.A.; Weinstein, R.A.; Sepkowitz, K.A.; Jernigan, J.A.; Sanogo, K.; et al. Effect of daily chlorhexidine bathing on hospital-acquired infection. N. Engl. J. Med. 2013, 368, 533-542. [CrossRef] [PubMed]

8. Vinšová, J.; Kozic, J.; Krátký, M.; Stolaříková, J.; Mandíková, J.; Trejtnar, F.; Buchta, V. Salicylanilide diethyl phosphates: Synthesis, antimicrobial activity and cytotoxicity. Bioorg. Med. Chem. 2014, 22, 728-737. [CrossRef] [PubMed]

9. Huczyński, A.; Rutkowski, J.; Popiel, K.; Maj, E.; Wietrzyk, J.; Stefańska, J.; Majcher, U.; Bartl, F. Synthesis, antiproliferative and antibacterial evaluation of C-ring modified colchicine analogues. Eur. J. Med. Chem. 2015, 90, 296-301. [CrossRef] [PubMed]

10. Emirdağ-Öztürk, S.; Karayıldırım, T.; Çapcı-Karagöz, A.; Alankuş-Çalışkan, Ö.; Özmen, A.; Poyrazoğlu-Çoban, E. Synthesis, antimicrobial and cytotoxic activities, and structure-activity relationships of gypsogenin derivatives against human cancer cells. Eur. J. Med. Chem. 2014, 82, 565-573. [CrossRef] [PubMed]

11. Gu, W.; Hao, Y.; Zhang, G.; Wang, S.F.; Miao, T.T.; Zhang, K.P. Synthesis, in vitro antimicrobial and cytotoxic activities of new carbazole derivatives of ursolic acid. Bioorg. Med. Chem. Lett. 2015, 25, 554-557. [CrossRef] [PubMed]

12. Harvey, A.L. Natural products in drug discovery. Drug Discov. Today 2008, 13, 894-901. [CrossRef] [PubMed]

13. Newman, D.J.; Cragg, G.M. Natural products as sources of new drugs over the 30 years from 1981 to 2010. J. Nat. Prod. 2012, 75, 311-335. [CrossRef] [PubMed]

14. Sun, H.D.; Huang, S.X.; Han, Q.B. Diterpenoids from Isodon species and their biological activities. Nat. Prod. Rep. 2006, 23, 673-698. [CrossRef] [PubMed]

15. Wang, L.; Li, D.H.; Wang, C.L.; Zhang, Y.H.; Xu, J.Y. Recent progress in the development of natural ent-kaurane diterpenoids with anti-tumor activity. Mini Rev. Med. Chem. 2011, 11, 910-919. [CrossRef] [PubMed]

16. Cha, J.Y.; Yeoman, J.T.S.; Reisman, S.E. A concise total synthesis of (-)-maoecrystal Z. J. Am. Chem. Soc. 2011, 133, 14964-14967. [CrossRef] [PubMed]

17. Gong, J.X.; Lin, G.A.; Sun, W.B.; Li, C.C.; Yang, Z. Total synthesis of ( \pm ) maoecrystal V. J. Am. Chem. Soc. 2010, 132, 16745-16746. [CrossRef] [PubMed]

18. Pan, Z.; Zheng, C.; Wang, H.; Chen, Y.; Li, Y.; Cheng, B.; Zhai, H. Total synthesis of ( \pm )-sculponeatin N. Org. Lett. 2014, 16, 216-219. [CrossRef] [PubMed]

19. Carpenter, A.W.; Schoenfisch, M.H. Nitric oxide release: Part II. Therapeutic applications. Chem. Soc. Rev. 2012, 41, 3742-3752. [CrossRef] [PubMed] 
20. Bogdan, C. Nitric oxide and the immune response. Nat. Immunol. 2001, 2, 907-916. [CrossRef] [PubMed]

21. Mocellin, S. Nitric oxide: Cancer target or anticancer agent? Curr. Cancer Drug Targets 2009, 9, $214-236$. [CrossRef] [PubMed]

22. Han, C.; Huang, Z.J.; Zheng, C.; Wan, L.D.; Zhang, L.W.; Peng, S.X.; Ding, K.; Ji, H.B.; Tian, J.D.; Zhang, Y.H. Novel hybrids of (phenylsulfonyl)furoxan and anilinopyrimidine as potent and selective epidermal growth factor receptor inhibitors for intervention of non-small-cell lung cancer. J. Med. Chem. 2013, 56, 4738-4748. [CrossRef] [PubMed]

23. Ai, Y.; Kang, F.; Huang, Z.; Xue, X.; Lai, Y.; Peng, S.; Tian, J.; Zhang, Y. Synthesis of CDDO-amino acid-nitric oxide donor trihybrids as potential antitumor agents against both drug-sensitive and drug-resistant colon cancer. J. Med. Chem. 2015, 58, 2452-2464. [CrossRef] [PubMed]

24. Fang, F.C. Antimicrobial reactive oxygen and nitrogen species: Concepts and controversies. Nat. Rev. Microbiol. 2004, 2, 820-832. [CrossRef] [PubMed]

25. Privett, B.J.; Broadnax, A.D.; Bauman, S.J.; Riccio, D.A.; Schoenfisch, M.H. Examination of bacterial resistance to exogenous nitric oxide. Nitric Oxide 2012, 26, 169-173. [CrossRef] [PubMed]

26. Backlund, C.J.; Worley, B.V.; Schoenfisch, M.H. Anti-biofilm action of nitric oxide-releasing alkyl-modified poly(amidoamine) dendrimers against Streptococcus mutans. Acta Biomater. 2016, 29, 198-205. [CrossRef] [PubMed]

27. Wang, L.; Li, D.; Xu, S.; Cai, H.; Yao, H.; Zhang, Y.; Jiang, J.; Xu, J. The conversion of oridonin to spirolactone-type or enmein-type diterpenoid: Synthesis and biological evaluation of ent-6,7-seco-oridonin derivatives as novel potential anticancer agents. Eur. J. Med. Chem. 2012, 52, 242-250. [CrossRef] [PubMed]

28. Fu, J.; Liu, L.; Huang, Z.; Lai, Y.; Ji, H.; Peng, S.; Tian, J.; Zhang, Y. Hybrid molecule from $\mathrm{O}^{2}$-(2,4-dinitrophenyl)diazeniumdiolate and oleanolic acid: A glutathione $S$-transferase $\pi$-activated nitric oxide prodrug with selective anti-human hepatocellular carcinoma activity and improved stability. J. Med. Chem. 2013, 56, 4641-4655. [CrossRef] [PubMed]

29. Fang, L.; Appenroth, D.; Decker, M.; Kiehntopf, M.; Lupp, A.; Peng, S.; Fleck, C.; Zhang, Y.; Lehmann, J. NO-donating tacrine hybrid compounds improve scopolamine-induced cognition impairment and show less hepatotoxicity. J. Med. Chem. 2008, 51, 7666-7669. [CrossRef]

30. Zhang, X.M.; Guo, H.; Li, Z.S.; Song, F.H.; Wang, W.M.; Dai, H.Q.; Zhang, L.X.; Wang, J.G. Synthesis and evaluation of isatin- $\beta$-thiosemicarbazones as novel agents against antibiotic-resistant Gram-positive bacterial species. Eur. J. Med. Chem. 2015, 101, 419-430.

31. Liao, J.; Yang, F.; Zhang, L.; Chai, X.; Zhao, Q.; Yu, S.; Zou, Y.; Meng, Q.; Wu, Q. Synthesis and biological evaluation of novel fluconazole analogues bearing 1,3,4-oxadiazole moiety as potent antifungal agents. Arch. Pharm. Res. 2015, 38, 470-479.

32. Chen, T.C.; Wu, C.L.; Lee, C.C.; Chen, C.L.; Yu, D.S.; Huang, H.S. Structure-based hybridization, synthesis and biological evaluation of novel tetracyclic heterocyclic azathioxanthone analogues as potential antitumor agents. Eur. J. Med. Chem. 2015, 103, 615-627.

33. Bi, Y.; Yang, X.; Zhang, T.; Liu, Z.; Zhang, X.; Lu, J.; Cheng, K.; Xu, J.; Wang, H.; Lv, G.; et al. Design, synthesis, nitric oxide release and antibacterial evaluation of novel nitrated ocotillol-type derivatives. Eur. J. Med. Chem. 2015, 101, 71-80.

34. Shen, T.; Li, W.; Wang, Y.Y.; Zhong, Q.Q.; Wang, S.Q.; Wang, X.N.; Ren, D.M.; Lou, H.X. Antiproliferative activities of Garcinia bracteata extract and its active ingredient, isobractatin, against human tumor cell lines. Arch. Pharm. Res. 2014, 37, 412-420.

35. Lepiarczyk, M.; Kałuża, Z.; Bielawska, A.; Czarnomysy, R.; Gornowicz, A.; Bielawski, K. Cytotoxic activity of octahydropyrazin[2,1-a:5,4-a']diisoquinoline derivatives in human breast cancer cells. Arch. Pharm. Res. 2015, 38, 628-641.

36. Yugandhar, D.; Nayak, V.L.; Archana, S.; Shekar, K.C.; Srivastava, A.K. Design, synthesis and anticancer properties of novel oxa/azaspiro[4,5]trienones as potent apoptosis inducers through mitochondrial disruption. Eur. J. Med. Chem. 2015, 101, 348-357.

(C) 2016 by the authors; licensee MDPI, Basel, Switzerland. This article is an open access article distributed under the terms and conditions of the Creative Commons Attribution (CC-BY) license (http://creativecommons.org/licenses/by/4.0/). 